\title{
Old or Age Indeterminate Lateral Myocardial Infarction by ECG Finding
}

National Cancer Institute

\section{Source}

National Cancer Institute. Old or Age Indeterminate Lateral Myocardial Infarction by ECG

Finding. NCI Thesaurus. Code C102690.

An electrocardiographic finding of pathologic Q waves in leads V5, V6, I and aVL, which is suggestive of myocardial infarction of the lateral wall of the left ventricle, without evidence of current or ongoing acute infarction. (CDISC) 